no further odor of nitrogen peroxide is discernible. The residue is dissolved in water up to the required strength.

The experiment is not above the reach of the ordinary high school student, and is one which will keep the restless, energetic boy busy during his laboratory periods, for at least two or three weeks. The following are the equations that express the principal reactions involved:

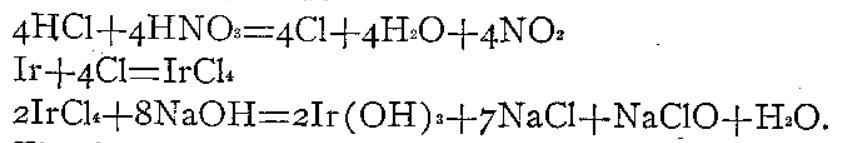

The few drops of alcohol decompose the sodium hypochlorite with the formation of acetaldehyde.

$\mathrm{NaClO}+\mathrm{C}_{2} \mathrm{H}_{6} \mathrm{O}=\mathrm{NaCl}+\mathrm{CH}_{3}, \mathrm{CHO}+\mathrm{H}_{2} \mathrm{O}$

$\operatorname{Ir}(\mathrm{OH})_{3}+3 \mathrm{HCl}=\mathrm{IrCl}_{3}+3 \mathrm{H}_{2} \mathrm{O}$.

The iridious chloride is not precipitated by potassium chloride while the hydro platinic chloride is precipitated.

$\mathrm{H}_{2} \mathrm{PlCl}+2 \mathrm{KCl}=\mathrm{K}_{2} \mathrm{PtCl}_{8}+2 \mathrm{HCl}$

$\mathrm{K}_{2} \mathrm{Cl}_{2}, \mathrm{PtCl}_{4}+4 \mathrm{H}=\mathrm{Pt}+2 \mathrm{KCl}+4 \mathrm{HCl}$

$\mathrm{Pt}+2 \mathrm{HCl}+4 \mathrm{Cl}=\mathrm{H}_{2} \mathrm{PtCl}$.

\title{
COOLING BY EXPANSION AND WARMING BY COMPRESSION.
}

Charles Emerson Peet,

Lervis Institute.

The following method of showing cooling by expansion, and condensation of the water vapor of the air into a visible cloud of water particles, may be of interest to instructors of physiography. It is a method I have used with success for several years. The apparatus necessary is: I. An air pump. 2. A bell jar. 3. A bottle with snug fitting cork, coated with vaseline. The bottle is corked and placed under the bell jar and the air is exhausted from the bell jar. The cork is pushed out of the bottle by the air inside. The sudden expansion causes cooling enough to condense the water vapor into a cloud which remains visible for a considerable time. Slow leakage of the air into the bell jar may produce warming by enough to re-evaporate the water. This warming by compression is made more striking if the bell jar is provided with a stop-cock by which the air may be admitted more rapidly and in a manner which is apparent to the class. The success of the experiment varies with the humidity of the air, but under the most unfavorable circumstances, it is never an entire failure. The size of bottle to be used and the force with which the cork should be pressed into it can easily be determined by trial. The cloud in the bottle may be made more clearly visible from the distance, of course, by providing it with a proper background. 